\title{
Multivariable Decoupling Controller: Application to Multicellular Converter
}

\author{
Abir Smati \\ Faculty of sciences of Tunis \\ LACS LAboratory \\ University of Tunis El Manar, Tunisia \\ Wassila Chagra \\ School of Engineering of Tunis \\ LACS LAboratory \\ University of Tunis El Manar, Tunisia
}

\author{
Denis Berdjag \\ University of Valenciennes, France \\ LAMIH LAboratory \\ Moufida Ksouri \\ School of Engineering of Tunis \\ LACS LAboratory \\ University of Tunis El Manar, Tunisia
}

\begin{abstract}
A new control strategy is presented in this paper, based on previous works limited to the control of the capacitor voltages considered as the outputs of a three cell converter. An additional control input is proposed to this latter in order to obtain the desired current output. The experimentations performed on a multicellular converter are presented and the discussed results showing the efficiency of the contribution.
\end{abstract}

Keywords-Hybride systems; Multicellular series converters; PWM; Closed loop control.

\section{INTRODUCTION}

Industrial applications require electric power which may vary from a few kilowatts to megawatts of power [1], [2]. In order to achieve that purpose, there is a need to control the electrical power from the source before sending it to the load, hence the appearance of multicellular serie converters that were designed in 1990. The device is a multistage serie converter used to distribute the elevated voltage of the power source by dividing it over several cells and limit constraints voltages undergone by the semiconductor components. The latter adopt a switching behavior, the semiconductors can be either closed or opened, which changes the operation mode of the converter depending on the states of the switches. Hence, the electrical power output can be adapted according to the required load. Each cell of the converter is constituted by alternatively operating the two switches (if one is open the other is closed and alternatively). The switches are considered ideal, so their behavior can be modeled by a discrete state: the open state (value $=0)$ and the closed state $($ value $=1)$. Therefore, this system can be considered a hybrid system [3], as it contains continuous dynamic changes related to discrete variations. In the case of multicellular converter, the importance of the control strategy comes from the need for electrical power adapted to the load, but the high speed switching of the semi conductors causes the appearance of several unwanted harmonics in the output signal. This is where the different control techniques can stand trying to eliminate this undesirable effect [4]. Other requirements may also come into play, such as the energy level performance and power losses that have repercussions on the converter topology. In [5] a binary control was developed based on a Lyapunov function where the author proposed an algorithm that limits the number of the switches commutations to extend their durability. In the control strategy proposed in [6] the authors present a nonlinear decoupling input to a three cell converter, which is able to obtain good performances in controlling the capacitors voltages without regards to the current output, in fact only its average value was controlled. This paper proposes an additional control input to stabilize the instant value of the current output.

The following section start by introducing the system. Section three presents a nonlinear decoupling input control. Section forth describe the control schemes used on an experimental setup. Section fifth will conclude this paper.

\section{Mathematical Modeling}

Multicellular converter series are the association of several cells separated by capacitors. Each cell is formed by two complementary switches. The voltages across each cell must be kept well-defined to ensure the proper functioning of the entire system values. The following structures can be DC-DC converters (chopper operation), or as DC-AC (inverter operation) [5]. In general, the structure for $\mathrm{p}$ cells multicellular, Fig.1, have $(p-1)$ capacitors, $2 p$ operating modes and $(p+1)$ voltage levels at the terminals of the capacitors.

In the case of a three cell converter there is eight operating modes. The following table gives the different configurations depending on the state of the switches $\left(S_{3}, S_{2}, S_{1}\right)$ and the corresponding output voltages.

For modeling a multi-converter, we have two models:

1) The Exact Model or Snapshot: This model is only used to validate the controls. It is accurate because it takes exactly the switch status (On or Off) at any time. $I_{c k}$ is the current through the capacitor and the signal $S_{k}=0,1$ are commands 
TABLE I: MODE CONFIGURATION OF A THREE CELLS CONVERTER

\begin{tabular}{|l|l|l|l|l|}
\hline & S3 & S2 & S1 & $V_{\text {out }}$ \\
\hline Mode 0 & 0 & 0 & 0 & 0 \\
\hline Mode 1 & 0 & 0 & 1 & $E / 3$ \\
\hline Mode 2 & 0 & 1 & 0 & $E / 3$ \\
\hline Mode 3 & 0 & 1 & 1 & $2 E / 3$ \\
\hline Mode 4 & 1 & 0 & 0 & $E / 3$ \\
\hline Mode 5 & 1 & 0 & 1 & $2 E / 3$ \\
\hline Mode 6 & 1 & 1 & 0 & $2 E / 3$ \\
\hline Mode 7 & 1 & 1 & 1 & $E$ \\
\hline
\end{tabular}

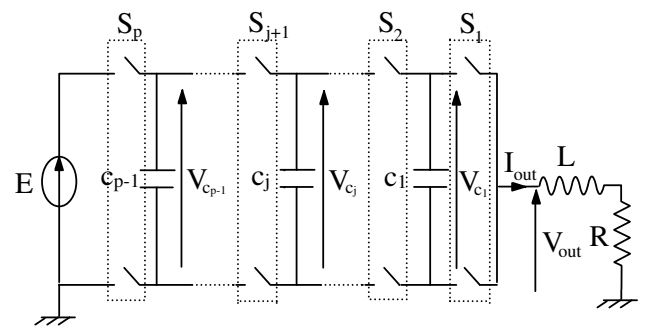

Fig. 1: Structure of a converter associated with a RL circuit as a load

of the switches $(\mathrm{k}=1,2,3)$. form:

The current as a function of the control signals is of the

$$
I_{c k}=\left(S_{k+1}-S_{k}\right) I_{o u t}
$$

Also it can have the next form depending on the voltage across the capacitors:

$$
I_{c_{k}}=C_{k}\left(\frac{d V_{c_{k}}}{d t}\right)
$$

Combining the two equations (1) and (2) gives:

$$
\left(\frac{d V_{c_{k}}}{d t}\right)=\left(\frac{S_{k+1}-S_{k}}{C_{k}}\right) I_{\text {out }}
$$

\section{2) Equations of the tensions:}

$$
\begin{aligned}
\frac{d V_{c_{1}}}{d t} & =\left(\frac{S_{2}-S_{1}}{C_{1}}\right) I_{\text {out }} \\
\frac{d V_{c_{2}}}{d t} & =\left(\frac{S_{3}-S_{2}}{C_{2}}\right) I_{\text {out }}
\end{aligned}
$$

3) Equations of the currents:

$$
\begin{aligned}
& I_{c_{1}}=C_{1}\left(\frac{d V_{c_{1}}}{d t}\right) \\
& I_{c_{2}}=C_{2}\left(\frac{d V_{c_{2}}}{d t}\right)
\end{aligned}
$$

According to the law of the meshes, the voltage Vs is the sum of the voltages across the switches:

$$
V_{\text {out }}=\sum_{k=1}^{p}\left(V_{c_{k}}-V_{c_{k-1}}\right) S_{k}
$$

Where $V_{c_{0}}=0 \mathrm{~V}$ and $V_{c_{p}}=E$. The evolution of the current in the load is given by:

$$
\frac{d I_{\text {out }}}{d t}=\frac{V_{\text {out }}}{L}-\frac{R}{L} I_{c}
$$

By substituting (8) we obtain:

$$
\frac{d I_{\text {out }}}{d t}=-\frac{R}{L} I_{c}-\left(\frac{S_{2}-S_{1}}{L}\right) V_{c_{1}}-\left(\frac{S_{3}-S_{2}}{L}\right) V_{c_{2}}+\frac{E}{L} S_{3}
$$

The state space model can be written as follows:

$\left(\begin{array}{c}\frac{d V_{c_{1}}}{d t} \\ \frac{d V_{c_{2}}}{d t} \\ \frac{d I_{\text {out }}}{d t}\end{array}\right)=\left(\begin{array}{ccc}0 & 0 & \frac{S_{2}-S_{1}}{C_{1}} \\ 0 & 0 & \frac{S_{3}-S_{2}}{C_{2}} \\ \frac{S_{1}-S_{2}}{L} & \frac{S_{2}-S_{3}}{L} & -\frac{R}{L}\end{array}\right)\left(\begin{array}{c}V_{c_{1}} \\ V_{c_{2}} \\ I_{\text {out }}\end{array}\right)+\left(\begin{array}{c}0 \\ 0 \\ \frac{E}{L} S_{3}\end{array}\right)$

An open loop control strategy was proposed in [7], were the control input is able to lead the system outputs to theirs corresponding references. The switches are controlled by pulses generated by the intersection between a triangular carrier signal and modulating, Fig. 2. The triangular signals are described by the following equations:

$$
\left\{\begin{array}{l}
f_{1}(u)=\left(\arcsin \left(\sin \left(2 \pi f_{p} t-\varphi\right)+\frac{\pi}{2}\right) / \pi\right. \\
f_{2}(u)=\left(\arcsin \left(\sin \left(2 \pi f_{p} t-\varphi-\delta\right)+\frac{\pi}{2}\right) / \pi\right. \\
\cdot \\
f_{p}(u)=\left(\arcsin \left(\sin \left(2 \pi f_{p} t-\varphi-(p-1) \delta\right)+\frac{\pi}{2}\right) / \pi\right.
\end{array}\right.
$$

The phase shift $\delta$ is equal to $2 \pi / p$ which would reduce the harmonics of the output signal.

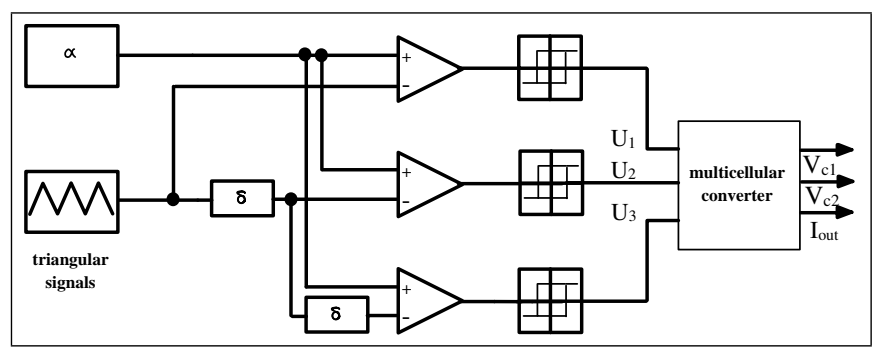

Fig. 2: PWM control strategy

The mentioned open loop control strategy generates several oscillations in the system outputs around their references. Also, the response of the system is very slow.

\section{A. The average values Model}

Let consider the system described in Fig. 2, the average model is based on the Fourrier series decomposition control signals. It allows a dynamic representation of the multicellular 
converter. It is assumed that the transitional regime is negligible. In this context, we can decompose in the Fourier series form each control function $S_{k}(t)$ as following [5]:

$$
S_{k}(t)=a_{0}+\sum_{p=1}^{+\infty}\left(a_{p} \cos \left(p \frac{2 \pi}{T_{D}} t\right)+b_{p} \sin \left(p \frac{2 \pi}{T_{D}} t\right)\right)
$$

with $a_{0}=\frac{1}{T_{D}} \int_{0}^{T_{D}} f(t) d t$ and $f(t)=\left\{\begin{array}{l}1 \text { for } t<t_{\alpha} \\ 0 \text { for } t_{\alpha}<t<T_{D}\end{array}\right.$ thus $a_{0}=\frac{1}{T_{D}} \int_{0}^{t_{\alpha}} d t=\frac{t_{\alpha}}{T_{D}}$

Having the duty cycle $\alpha=\frac{t_{\alpha}}{T_{D}}$ leads to $a_{0}=\alpha$

In addition, the function $S_{k}(t)$ is pair, so $b_{p}=0$ and

$$
\begin{aligned}
& a_{p}=\frac{2}{T_{D}} \int_{0}^{T_{D}} f(t) \cos \left(p \frac{2 \pi}{T_{D}} t\right) d t \\
= & \frac{2}{T_{D}} \int_{0}^{\alpha_{k} T_{D}} \cos \left(p \frac{2 \pi}{T_{D}} t\right) d t=u_{k p}\left(\alpha_{k}\right)
\end{aligned}
$$

Hence, the Fourier series decomposition of the control function has the following expression:

$$
S_{k}(t)=\alpha_{k}+\sum_{p=1}^{+\infty}\left(u_{k p}\left(\alpha_{k}\right) \cos \left(p \frac{2 \pi}{T_{D}} t\right)\right)
$$

When passing to the average value equation (14) becomes $<S_{k}(t)>=\alpha_{k}$.

Each control variable is replaced by its average value over a period $T_{D}$, so the exact model described by equations (6), (7) and (8) becomes:

$$
\left\{\begin{array}{l}
<I_{c 1}>=\left(\alpha_{2}-\alpha_{1}\right) I_{\text {out }} \\
<I_{c 2}>=\left(\alpha_{3}-\alpha_{2}\right) I_{\text {out }} \\
<V_{\text {out }}>=\alpha_{3} E+V_{c 1}\left(\alpha_{1}-\alpha_{2}\right)+V_{c 2}\left(\alpha_{2}-\alpha_{3}\right)
\end{array}\right.
$$

It uses the duty ratio as information for the switching cell.

Assuming floating voltages do not vary very much on the chopping period [7], we obtain: $V_{c k_{m o y}}(t) \approx V_{c k}(t)$ which leads to the following equations:

$$
\left\{\begin{array}{l}
\frac{d V_{c_{k}}}{d t}=\frac{\left(\alpha_{k+1}-\alpha_{k}\right)}{c_{k}} I_{\text {out }} \\
V_{\text {out }_{\text {moy }}}=\sum_{k=1}^{p}\left(V_{c_{k}}-V_{c_{k-1}}\right) \alpha_{k}
\end{array}\right.
$$

So the average values model of a three cells converter will be as follows:

$$
\begin{aligned}
& \left(\begin{array}{c}
\frac{d V_{c_{1}}}{d t} \\
\frac{d V_{c_{2}}}{d t} \\
\frac{d I_{\text {out }}}{d t}
\end{array}\right)=\left(\begin{array}{ccc}
0 & 0 & 0 \\
0 & 0 & 0 \\
0 & 0 & -\frac{R}{L}
\end{array}\right)\left(\begin{array}{c}
V_{c_{1}} \\
V_{c_{2}} \\
I_{\text {out }}
\end{array}\right) \\
& +\left(\begin{array}{ccc}
-\frac{I_{\text {out }}}{c_{1}} & \frac{I_{\text {out }}}{c_{1}} & 0 \\
0 & -\frac{I_{\text {out }}}{c_{2}} & \frac{I_{\text {out }}}{c_{2}} \\
-\frac{V_{c_{1}}}{L} & -\frac{V_{c_{2}}}{L} & \frac{E}{L}
\end{array}\right)\left(\begin{array}{l}
\alpha_{1} \\
\alpha_{2} \\
\alpha_{3}
\end{array}\right)
\end{aligned}
$$

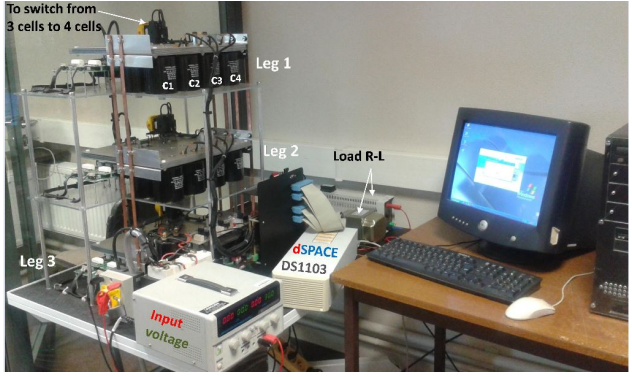

Fig. 3: The experimental setup

\section{MATERIALS}

The platform used to validate the next control technique is a system constituted of three legs initially connected to a three phase motor and replaced by a R-L load ( $R=20 \Omega, L=0.01 \mathrm{mH}$ ) for this application. We used a three-cell converter, see Fig. 3. The value of the capacitors between the cells are $C_{1}=C_{2}=C=40 \mu \mathrm{F}$. The switches are bipolar transistors (IGBTs). Current and voltage measurements are obtained from voltage sensors and current transductors. The voltage source of the converter is $E=60 \mathrm{~V}$. A Matlab program script implementing the predictive algorithm was compiled and run by a DSPACE card. The card is used to control switch gates using its binary outputs, and receives measurements of the current and the two capacitor voltages through input card.

\section{EXPERIMENTAL RESULTS OF PWM CONTROL}

The PWM (Pulse Width Modulation) control is a standard technique which can be used in case having a prime number of the cells in the converter [5]. It allows the control of the output current while keeping the voltages across the capacitors around the reference values.

We proceed with having: $\beta_{3}=\alpha_{3}-\alpha_{1}$ and $\beta_{2}=\alpha_{2}-\alpha_{1}$ we obtain:

$$
\left(\begin{array}{l}
C_{1} \frac{d V_{c_{1}}}{d t} \\
C_{2} \frac{d V_{c_{2}}}{d t}
\end{array}\right)=\left(\begin{array}{cc}
1 & 0 \\
-1 & 1
\end{array}\right)\left(\begin{array}{l}
\beta_{2} \\
\beta_{3}
\end{array}\right) I_{\text {out }}
$$

And therefore:

$$
\left(\begin{array}{c}
\beta_{2} \\
\beta_{3}
\end{array}\right)=\frac{1}{I_{\text {out }}}\left(\begin{array}{cc}
1 & 0 \\
-1 & 1
\end{array}\right)^{-1}\left(\begin{array}{l}
C_{1} \frac{d V_{c_{1}}}{d t} \\
C_{2} \frac{d V_{c_{2}}}{d t}
\end{array}\right)
$$

If $c_{1} \frac{d V_{c_{1}}}{d t}$ and $c_{2} \frac{d V_{c_{2}}}{d t}$ are replaced by $\gamma_{2}$ and $\gamma_{3}$ we obtain

$$
\left\{\begin{array}{l}
\beta_{2}=\frac{\gamma_{2}}{I_{\text {out }}} \\
\beta_{3}=\frac{\gamma_{3}+\gamma_{2}}{I_{\text {out }}}
\end{array}\right.
$$


Equation (20) is replaced in (15) leading to:

$$
\left\{\begin{array}{l}
<I_{c 1}>=c_{1} \frac{d V_{c_{1}}}{d t}=\beta_{2} I_{\text {out }}=\gamma_{2} \\
<I_{c 2}>=c_{2} \frac{d V_{c_{2}}}{d t}=\left(\beta_{3}-\beta_{2}\right) I_{\text {out }}=\gamma_{3} \\
<V_{\text {out }}>=\left(\alpha_{1}+\frac{\gamma_{2}}{I_{\text {out }}}+\frac{\gamma_{3}}{I_{\text {out }}}\right) E-\frac{\gamma_{2}}{I_{\text {out }}} V_{c 1}-\frac{\gamma_{3}}{I_{\text {out }}} V_{c 2}
\end{array}\right.
$$

From the system equations (21) we can see that $\frac{d V_{c_{1}}}{d t}$ and $\frac{d V_{c_{2}}}{d t}$ are decoupled but $<V_{\text {out }}>$ remain coupled. So, another decoupling control input is added to control the average value of the current output.

Suppose that $\left\langle V_{\text {out }}\right\rangle=V_{\text {ref }}=R I_{\text {ref }}$, from equation (15) a decoupling control input can be as follows:

$$
\alpha_{1}=\frac{1}{V_{c 1}}\left[V_{r e f}-\alpha_{3}\left(E-V_{c 2}\right)+\alpha_{2}\left(V_{c 2}-V_{c 1}\right)\right]
$$

The principle is illustrated in the following figure 4 for a threecell converter. Two controllers (PI) are assigned for regulating $V_{c 1}$ and $V_{c 2}$.

In [5], the control strategy is able to drive the output volt-

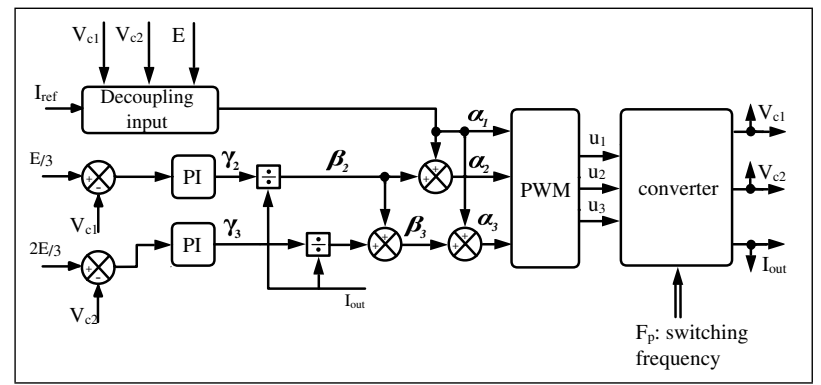

Fig. 4: Closed loop control strategy applied to a three-cell converter

ages to their desired values but the current response presents several undulations around its set-point as shown in Fig. 5. The reason is related to the average model used in the control input (22) which lead obviously to control only the average value of the current output and not its instantaneous value, thus it allows the appearance of several oscillations around its reference.

To solve this problem, we associate another control term $\gamma_{1}$ that will be the output of a PI controller, the idea is inspired from [8] were the author combine a PID control action with a nonlinear control law. Thus the final expression controlling the current output will be the sum of a decoupling action and a PI control action.

$\alpha_{1}=\frac{1}{V_{c 1}}\left[R I_{r e f}-\alpha_{3}\left(E-V_{c 2}\right)+\alpha_{2}\left(V_{c 2}-V_{c 1}\right)+\gamma_{1}\right]$

Which leads to a new structure of the overall control strategy (figure 6). An experimental results of the presented control scheme is conducted, where the frequency of the triangular signals $f_{p}=1800 \mathrm{~Hz}$ and the output references are as follows: $V_{c 1_{r e f}}=\frac{E}{3}, V_{c 2_{r e f}}=2 \frac{E}{3}$ and $I_{r e f}=1.5 \mathrm{~A}$. The results are shown in Fig. 7, where it is shown that all the outputs follow theirs desired values.
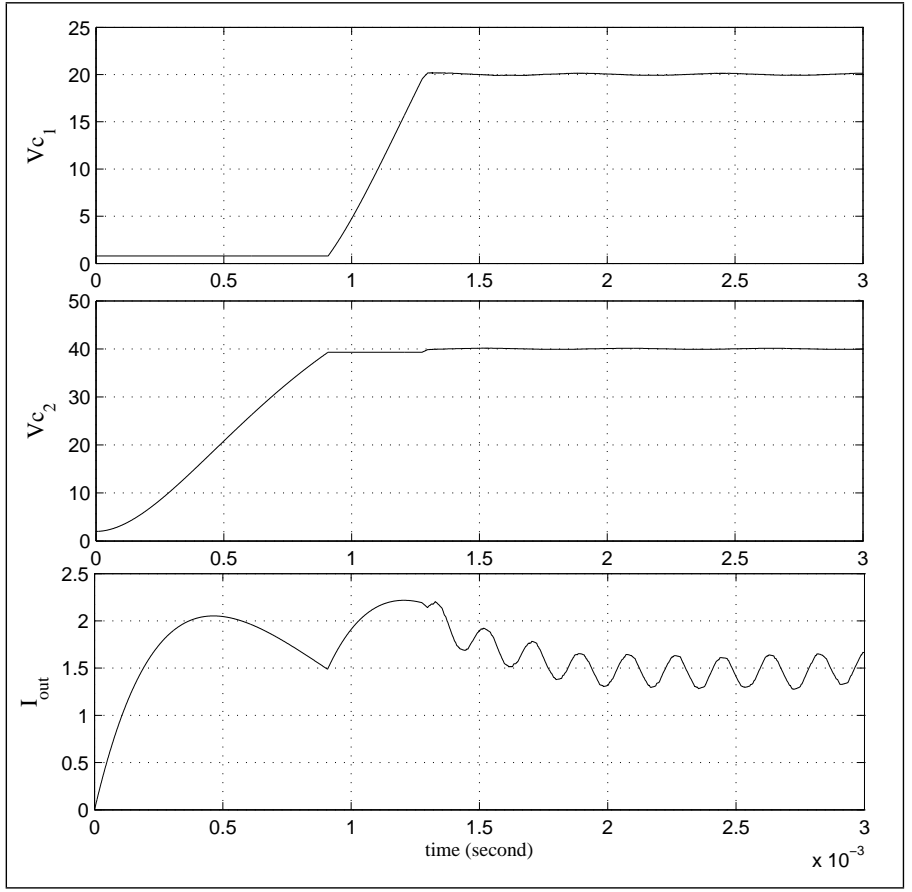

Fig. 5: Experimental results of the voltages across the capacitors $\left(V_{c 1}\right.$ and $\left.V_{c 2}\right)$ and the current output $\left(I_{o u t}\right)$ evolution

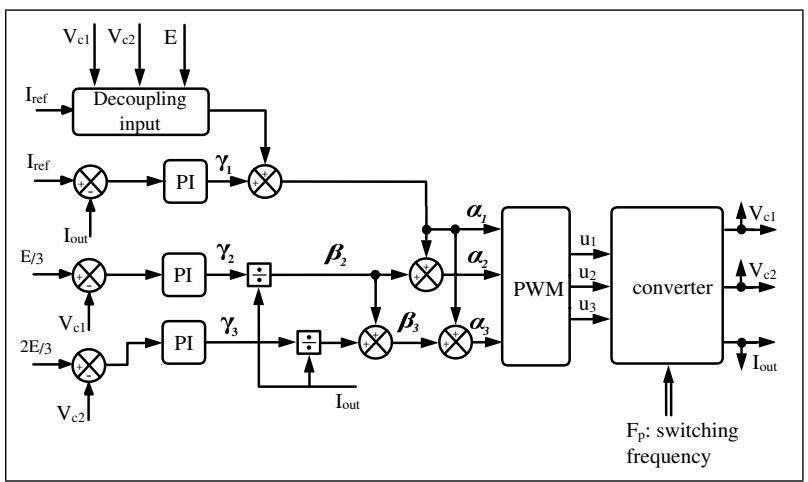

Fig. 6: The new proposed closed loop control strategy applied to a three-cell converter

\section{CONCLUSION}

Multicell converters are widely used in industrial applications because they offer the solution to control the electric energy between the source and the load. But, because of the discrete dynamic behavior of the semiconductors components, the system outputs present adverse effects (harmonics) that is possible to attenuate through an optimal control. The proposed control presented in this paper is based on an average model of the system, were after decoupling the system outputs from their inputs, we proceed to control the capacitor voltages. But, a problem arises in the current output were the decoupling control is not enough to attain good performances. In order to solve this problem, we added a PI control to the control input leading to acceptable performances. 


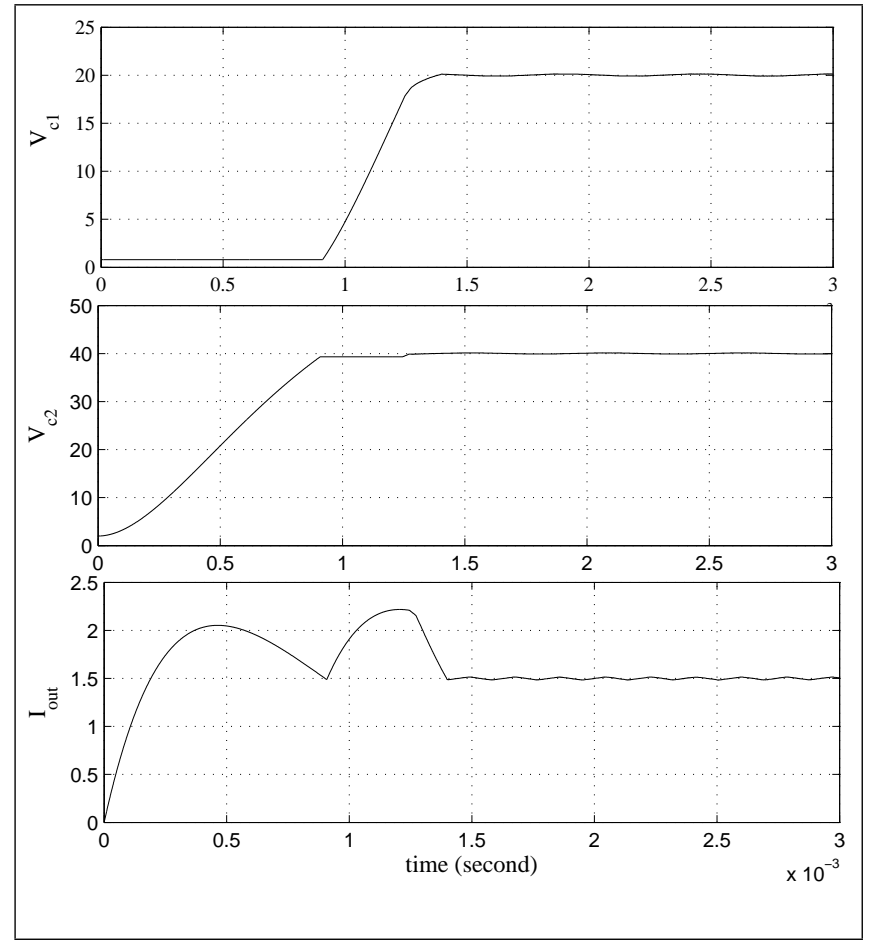

Fig. 7: Experimental results of the voltages across the capacitors $\left(V_{c 1}\right.$ and $\left.V_{c 2}\right)$ and the current output $\left(I_{o u t}\right)$ evolution

\section{ACKNOWLEDGMENT}

This work was realized with the collaboration between ACCS (laboratory of Analysis, Control and Conception of electronic Systems from the National School of Engineering of Tunis el Manar) and LAMIH (Laboratory of Industrial and Human Automation control, Mechanical engineering and Computer Science, Valenciennes, France). We adress our thanks to to the Ministry of Higher Education and Scientific Research of Tunisia for funding and supports.

\section{REFERENCES}

[1] G. Gateau and M. Fades, Multicellar converters : Active control and observation of flying capacitor voltages, IEEE Trans. Industrial Electronics, Vol. 49, No. 5, 2002.

[2] T. A. Meynard, H. Foch, P. Thomas, J. Courault, R. Jakob, and M. Nahrstaedt, Multicell converters: basic concepts and industry applications, IEEE Transactions on Industrial Electronics, vol. 49, pp. 955964 october 2002.

[3] K. Benmansour, A. Benalia , M. Djemai and J. deLion Hybrid control of a multicellular converter, non linear analysis: Hybrid system, 2007.

[4] P. Bartholomeus and $\mathrm{Ph}$. Le Moigne. A simple method for the valuation of the harmonics generated by multilevel converters. ELECTRIMACS'96, Saint Nazaire, 17-18-19 Sept. 1996.

[5] O. Béthoux, " Commande et Détection de Défaillance d'un Convertisseur Multicellulaire Série ", Thèse de doctorat, Université de Cergy-Pontoise, pp. 16-18; 2005.

[6] J. Van Gorp, M. Defoort and M. Djemai, Binary signals design to control a power converter, 50th IEEE Conference on Decision and Control and European Control Conference (CDC-ECC) pp.12-15, Orlando, FL, USA, December , 2011

[7] M.Aimé, 'Évaluation et optimisation de la bande passante des convertisseurs statiques : Application aux nouvelles structures multicellulaires", Thèse de doctorat, INPT, pp . 92-95, 2003.
[8] L. Michel, W. Michiels and X. Boucher, Model-free control of nonlinear power converter, The Canadian Conference on Electrical and Computer Engineering, 2013. 